\title{
The Relationships among Teacher Perceptions on Professional Learning Community, Collective Efficacy, Gender, and School Level
}

\author{
Su-ching Lin, $P h . D$. \\ Professor, Department of Education, National Changhua University of Education \\ 1, Jin De Road, Paisha Village, Changhua 500, Taiwan \\ Tel: 886-47232105\# $5701 \quad$ E-mail: sclin@cc.ncue.edu.tw
}

Received: Oct. 5, 2013 Accepted: October 21, 2013 Published: November 1, 2013

doi:10.5296/jse.v3i4.4387 URL: http://dx.doi.org/10.5296/jse.v3i4.4387

\begin{abstract}
This study examined the relationships among teacher perceptions on professional learning community (PLC), collective efficacy (CE), gender, and school level. The participants were 486 elementary school and secondary school teachers in Taiwan. The analytical results showed a positive correlation between teacher perceived PLC and CE, i.e., perceived PLC could predict perceived CE. At task analysis level, the PLC dimension human and social resource was strongest predictor of perceived CE. At group competence level, however, the core element dimension was the best predictor. Moreover, elementary school teachers differed significantly from their secondary school counterparts in perceived CE.
\end{abstract}

Keywords: Professional learning community, Collective efficacy, Secondary school, Elementary school 


\section{Introduction and purposes}

Establishing a professional learning community (PLC) of teachers is considered a systematic and effective way to improve teacher qualities and student learning in various dimensions (Goddard, Hoy, \& Woolfolk Hoy, 2004; Thompson, Gregg, \& Niska, 2004). Kruse and Louis (1993) proposed that establishing a PLC can contribute to several potential advantages for schools. Among them are the development of collective responsibility of teachers for student learning performance and instructional performance of teachers; the enhancement of personal commitment to their work; the establishment of values, norms and beliefs in the instrumental control mechanism for student achievement; and the establishment of flexible boundaries for greater organizational learning.

According to the literature (e.g., DuFour, DuFour, \& Eaker, 2008; Hord, 1997; Stoll, Bolam, McMahon, Wallace, \& Thomas, 2006), PLCs are characterized by supportive and shared leadership, shared values and vision, reflective dialogue, collective learning and application, supportive conditions, shared personal practice, and results orientation. These characteristics emerge when a group of teachers collaboratively and critically exchange their instructional practices in an ongoing, reflective, inclusive, learning-oriented, and growth-promoting way to support innovation and knowledge sharing (Mitchell \& Sackney, 2000; Stoll \& Louis, 2007).

According to Bandura (1997), collective efficacy (CE) can be defined as the shared beliefs of a group in its conjoined capabilities to execute the courses of action required to achieve assigned goals. Collective efficacy beliefs emphasize that of teachers result in self-referent efficacy perceptions and beliefs about the conjoint capability of a school faculty. Within an organization, perceived collective efficacy represents the beliefs of group members concerning the performance capability of the overall social system (Bandura, 1997; Hodges \& Carron, 1992; Goddard, 2001; Peterson, Mitchell, Thompson, \& Burr, 2000). For schools, perceived collective efficacy refers to the belief by teachers that the overall faculty can organize and execute the courses of action required to have a positive effect on students (Goddard, Hoy, \& Woolfolk Hoy, 2004).

Because of the unprecedented K-12 educational reforms recently implemented in Taiwan, PLCs have received considerable attention, especially at the elementary and secondary school levels. Taiwanese government is encouraging different school levels to build open and collaborative PLCs to promote teacher involvement and to enable continuous improvement in their professional skills. Teachers are encouraged to change their traditional views and perceive themselves as peers who practice collaboratively engagement in professional discussion. Increasing numbers of teachers are seeking to upgrade their professional competencies by attending PLCs within their own schools. All of these events are important steps in developing a PLC.

A PLC is considered a collaborative community for exchanging teaching experiences and for improving pedagogical professionalism. A PLC is believed to enhance the CE of teachers. Although the literature includes many studies of the characteristics and operation of PLCs (e.g., DuFour, DuFour, \& Eaker, 2008; Hord, 2004), little is still known about the relationship between PLC and CE. The few relevant studies include Lee, Zhang, and Yin's 
study (2011), who translated the collective teacher belief scale developed by Tschannen-Moran and Barr (2004) to measure two dimensions of teacher perceptions of CE, including instructional strategies and student discipline. Teacher perceptions of PLC were measured on three dimensions, namely, shared and supportive leadership, collective learning and application, and supportive conditions-structures. The measurement results indicated that all three PLC factors could significantly and positively affect teacher CE in instructional strategies. However, shared and supportive leadership and supportive conditions-structures were not significant predictors of teacher $\mathrm{CE}$ in maintaining student discipline. In contrast, collective learning and application was indeed significantly and positively related to teacher CE in student discipline (Lee, Zhang \& Yin, 2011). Therefore, PLC and CE are interrelated.

In contrast, the meaning and measure of teacher $\mathrm{CE}$ have attracted the subject of considerable interest among scholars and researchers. Goddard, Hoy, and Woolfolk Hoy (2000) broadened the conceptualization of collective efficacy beliefs by including elements of locus of control theory in its constitutive properties. Their hypothesized model accounts for efficacy sources proposed by Bandura $(1986,1993)$ and for the school conditions that affect how teachers analyze teaching tasks and how teaching competence is assessed. Thus, based on the concept the hypothesized model developed by Goddard, Hoy, and Woolfolk Hoy, the present study measured two dimensions of teacher perceptions of CE: task analysis and group competence. The relationship between perceived PLC and CE, including correlation and prediction in Taiwan context was examined. Perceived PLC and CE might also be affected by variables such as characteristics of individual teachers and schools (Adams and Forsyth, 2006; Bandura, 1993; Chester \& Beaudin, 1996; Hoy, Smith \& Sweetland, 2003; Tschannen-Moran \& Woolfolk Hoy, 1998). Thus, understanding whether gender and school levels affect perceived PLC and CE in different cultural contexts is also essential. The findings are expected to provide valuable information in this field and to enhance understanding of PLCs and CE in different cultural contexts.

\section{Methodology}

\subsection{Participants}

Fifth-eight elementary (including 118 PLCs) and thirteen secondary schools (including 29 PLCs) were randomly selected in central Taiwan to take part in this study. 500 teachers from these schools were invited to complete teacher PLC and CE questionnaires. To ensure confidentiality, each questionnaire was completed anonymously. With a response rate of 97.2\%, 486 teachers returned completed questionnaires, including 50.6\% elementary school teachers and $49.4 \%$ secondary school teachers. Of whom, $69.3 \%$ were female and $30.7 \%$ were male.

\subsection{Instruments}

\subsubsection{Perceived PLC}

One research instrument, the Perceived Professional Learning Communities Scale (PLCS) was developed based on the concepts of previous literature (DuFour, DuFour, \& Eaker, 2008; Hord, 1997, 2004; Kruse \& Louis, 1993) to measure teacher- perceived PLC on three 
dimensions, namely, core elements, human and social resources, and structural conditions. Fourteen items in this PLCS were designed to measure three dimensions. The first dimension, core elements (6 items) measured the teachers in term of reflective dialogue, shared values and vision, shared practice, collective learning and application of learning. The second dimension, human and social resources (4 items) measured physical conditions and human capacities of the school, which encourage and sustain a collegial atmosphere and collective learning. The third dimension, structural conditions (4 items) measured supportive environment of internalized connection between teachers in academic work, such as time to meet and talk, physical proximity, interdependent teaching roles, and communication structures. Teachers were asked to rate the items on a four-point Likert scale anchoring at 1, 2, 3 , and 4 (strongly disagree, disagree, agree, strongly agree).

The factor analysis made on data obtained by PLCS in the current application reveals that each item in all subscale dimensions produced factor loadings above .70. The overall internal consistency (Cronbach's $\alpha=$. 93) for the scale in the current sample was good. The Cronbach's $\alpha$ for the three subscales ranged from .81 to .90 , indicating good internal consistencies of the items within each subscale.

\subsubsection{Perceived CE}

Another one research instrument, the Perceived Collective Efficacy Scale (PCES), was developed on based on the concept of Goddard, Hoy, and Woolfolk Hoy's model (2000) to measure a teacher-perceived CE on two dimensions, namely, task analysis and group competence. Eight items in this PCES were designed to measure two dimensions.

The first dimension, task analysis (3 items), measured the teacher beliefs about what constitutes successful teaching in their schools, what barriers or limitations must be overcome, and what resources are available to achieve success. The second dimensions, group competence (5 items) in conjunction with their assessment of the teaching competency of the faculty including the faculty's teaching skills, methods, training, and expertise. Teachers were asked to rate the items on a four-point Likert scale anchoring at 1,2, 3, and 4 (strongly disagree, disagree, agree, strongly agree).

The factor analysis made on data obtained by PCES in the current application reveals that each item in all subscale dimensions produced factor loadings above .70. The overall internal consistency (Cronbach's $\alpha=$. 86) for the scale in the current sample was good. The Cronbach's $\alpha$ for the three subscales ranged from .83 to .86 , indicating good internal consistencies of the items within each subscale.

\subsection{Data analysis}

The statistical program SPSS 20.0 for windows was used for data analysis. First of all, three composite scores of core elements, human and social resources, and structural condition were computed for each respondent by adding the scores on the14, 6, 4, and 4 items in the perceived PLC scale respectively measuring total PLC, core elements, human and social resources, and structural condition. Similarly, a total perceived CE score as well as two additional composite $\mathrm{CE}$ scores were computed by adding the scores on the 8, 3 and 5 items, 
respectively, measuring total CE, task analysis and group competence. Descriptive statistics and product moment correlation coefficients were then computed for all variables in order to examine relationships among teacher gender, school level, perceived PLC and CE. In addition, a series of $t$-tests was used to compare teacher gender (male, female) and school level (elementary, secondary) as independent variables on the categories of perceived PLC and $\mathrm{CE}$ as dependent variables. Finally, regression analysis was used to test with task analysis and group competence as dependent variables and core element, human and social resources, structural condition, gender, and school level as independent variables to determine if the teacher perceived PLC predicted perceived CE.

\section{Results}

All statistical tests used to address the questions in this study used .05 as the minimum alpha level. The following tables present some descriptive statistics about variables as well as highlights from the inter-correlations matrix of the variables and the results of the independent sample $t$-test, Pearson product-moment correlation, and multiple regression analysis run in this study.

\section{1 difference analyses in gender and school level on teacher-perceived PLC and CE}

Table 1 showed difference analysis results, which indicated that a significant difference between male teachers and female teachers in human and social resources dimension $(t=2.25$, $p<.05)$. However, no significant differences were found between male teachers and female teachers in another two dimensions (core element, structural conditions). Table 1 also indicated a significant difference between elementary school teachers and secondary school teachers in core element dimension $(t=-2.22, p<.05)$. In contrast, no significant differences were found between elementary teachers and secondary teachers in human and socialresource dimension and in structural-condition dimension.

Table 1. $t$-tests of gender and school level on dimensions of perceived PLC

\begin{tabular}{lccccccccccc}
\hline & \multicolumn{3}{c}{$\operatorname{male}(\mathrm{n}=149)$} & \multicolumn{6}{c}{ female $(\mathrm{n}=337)$} & \multicolumn{5}{c}{ secondary $(\mathrm{n}=240)$} & \multicolumn{5}{c}{ elementary $(\mathrm{n}=246)$} \\
Dimension & $\mathrm{M}$ & $\mathrm{SD}$ & $\mathrm{M}$ & $\mathrm{SD}$ & $t$ & $\mathrm{M}$ & $\mathrm{SD}$ & $\mathrm{M}$ & $\mathrm{SD}$ & $t$ \\
\hline core element & 3.33 & .44 & 3.33 & .47 & .02 & 3.28 & .49 & 3.38 & .42 & $-2.22^{*}$ \\
H \& S resources & 3.21 & .48 & 3.10 & .47 & $2.25^{*}$ & 3.14 & .49 & 3.14 & .46 & .10 \\
S conditions & 3.33 & .47 & 3.26 & .48 & 1.61 & 3.25 & .50 & 3.31 & .46 & -1.43 \\
\hline
\end{tabular}
$* p<.05$

Table 2 showed difference analysis results, which indicated that significant differences between elementary school teachers and secondary school teachers in the task analysis dimensions $(t=-2.18, p<.05)$ and in the group competence dimension $(t=-3.33, p<.01)$. However, no differences were found between male teachers and female teachers in these two dimensions.

Table 2. $t$-tests of gender and school level on dimensions of perceived CE

\begin{tabular}{|c|c|c|c|c|c|c|c|c|c|c|}
\hline \multirow[b]{2}{*}{ Dimension } & \multicolumn{2}{|c|}{ male $(n=149)$} & \multicolumn{2}{|c|}{ female $(n=337)$} & \multicolumn{3}{|c|}{ secondary $(\mathrm{n}=240)$} & \multicolumn{2}{|c|}{ elementary $(n=246)$} & \multirow[b]{2}{*}{$t$} \\
\hline & $\mathrm{M}$ & $\mathrm{SD}$ & $\mathrm{M}$ & $\mathrm{SD}$ & $t$ & $\mathrm{M}$ & $\mathrm{SD}$ & $\mathrm{M}$ & SD & \\
\hline Task analysis & 3.28 & .44 & 3.24 & .44 & .76 & 3.21 & .46 & 3.30 & .41 & $-2.18^{*}$ \\
\hline Group competence & 3.22 & .60 & 3.17 & .58 & .77 & 3.10 & .61 & 3.27 & .55 & $-3.33^{* *}$ \\
\hline
\end{tabular}




\subsection{The prediction of perceived PLC and CE from teacher gender and school level}

Table 3 and Table 4 showed the results of regression analysis of the prediction of overall perceived PLC from teacher gender and from school level. The tables showed that teacher-perceived PLC could not be predicted from teacher gender $(\beta=.06 ; p=.197)$ and school level $(\beta=-.07 ; p=.132)$.

Table 3. The prediction of perceived PLC at overall level from teacher gender

\begin{tabular}{lcccrcrc}
\hline & $B$ & Standard error & $\beta$ & $t$ & $p$ & Zero-ordered $r$ & Part $r$ \\
\hline Constant & 3.25 & .02 & & 146.04 & .000 & & \\
Gender & .05 & .04 & .06 & 1.30 & .197 & .06 & .06 \\
\hline
\end{tabular}

$R=0.06, R^{2}=0.00$

$F(1,484)=10.96, p=0.000$

$\mathrm{PLC}$ at overall level $=3.25+0.05$ gender

Table 4. The prediction of perceived PLC at overall level from school level

\begin{tabular}{lccccccc}
\hline & $B$ & Standard error & $\beta$ & $t$ & $p$ & Zero-ordered $r$ & Part $r$ \\
\hline Constant & 3.29 & .03 & & 126.52 & .000 & & \\
School level & -.06 & .04 & -.07 & -1.51 & .132 & -.07 & -.07 \\
\hline
\end{tabular}

$R=0.07, R^{2}=0.01$

$F(1,484)=10.96, p=0.000$

PLC at overall level $=3.29-0.06$ school level

Table 5 and Table 6 showed the results of regression analysis of the prediction of overall perceived CE from teacher gender and from school level. The table 5 showed that teacher-perceived CE could not be predicted from teacher gender $(\beta=.07 ; p=.159)$. However, Table 6 showed that teacher-perceived CE could be predicted from school level $(\beta=-.12 ; p<.01)$.

Table 5. The prediction of perceived CE at overall level from teacher's gender

\begin{tabular}{lccrrrrr}
\hline & $B$ & Standard error & $\beta$ & $t$ & $p$ & Zero-ordered $r$ & Part $r$ \\
\hline Constant & 3.22 & .02 & & 153.45 & .000 & & .07 \\
Gender & .06 & .04 & .07 & 1.59 & .112 & .07 & .07 \\
\hline
\end{tabular}

$R=0.07, R^{2}=0.01$

$F(1,484)=10.96, p=0.000$

$\mathrm{CE}$ at overall level $=3.22+0.06$ gender

Table 6. The prediction of perceived CE at overall level from school level

\begin{tabular}{lccccccc}
\hline & $B$ & Standard error & $\beta$ & $t$ & $p$ & Zero-ordered $r$ & Part $r$ \\
\hline Constant & 3.29 & .02 & & 134.31 & .000 & & \\
school level & -.09 & .04 & -.12 & -2.64 & .009 & -.12 & -.12 \\
\hline
\end{tabular}

$R=0.12, R^{2}=0.01$

$F(1,484)=10.96, p=0.000$

$\mathrm{CE}$ at overall level $=3.29-0.10$ school level 


\subsection{Correlational analysis between perceived PLC and CE}

Table 7 showed the correlational analysis results, which indicated that, at overall level, perceived PLC was significantly and positively correlated with CE $(r=.60, p<.001)$. At the core element level, PLC had a significant positive relationship with task analysis $(r=.42, p$ $<.001)$ and with group competence $(r=.48, p<.001)$. At the human and social resources level, PLC had a significant positive relationship with task analysis $(r=.46, p<.001)$ and with group competence $(r=.48, p<.001)$. At the structural condition level, PLC had a significant positive relationship with task analysis $(r=.44, p<.001)$ and with group competence $(r=.49, p$ $<.001)$.

In summary, positive correlations were found among the three PLC dimensions, (core element, human and social resources, and structural conditions) and among the two CE dimensions (task analysis and group competence).

Table 7. Pearson product-moment correlation between perceived PLC and perceived CE $(\mathrm{n}=486)$

\begin{tabular}{lcccc}
\hline \multicolumn{1}{c}{$P L C$} & Core element & $\begin{array}{c}\text { Human and social } \\
\text { resources }\end{array}$ & $\begin{array}{c}\text { structural } \\
\text { conditions }\end{array}$ & total \\
\hline task analysis & & $.46^{* * *}$ & $.44^{* * *}$ & $.50^{* * *}$ \\
group competence & $.42^{* * *}$ & $.48^{* * *}$ & $.49^{* * *}$ & $.56^{* * *}$ \\
total & $.48^{* * *}$ & $.53^{* * *}$ & $.53^{* * *}$ & $.60^{* * *}$ \\
\hline${ }^{* * *} p<.001$ & $.51^{* * *}$ & &
\end{tabular}

\subsection{The prediction of perceived CE from perceived PLC}

Table 8 showed the results of regression analysis of the prediction of overall perceived $\mathrm{CE}$ from PLC. The table showed that teacher perceptions of $\mathrm{CE}$ at the overall level were significantly associated with each PLC dimension. The human and social resource dimension was apparently the best predictor of perceived CE at overall level $(\beta=.20 ; p<.001)$. Core element $(\beta=.19 ; p<.001)$ and structural condition $(\beta=.17 ; p<.001)$ were also significantly associated with $\mathrm{CE}$ at overall level. The PLC dimensions explained $36 \%$ of the variance in perceived $\mathrm{CE}$ at the overall level $\left(\mathrm{R}=.60 ; \mathrm{R}^{2}=.36\right.$ and $\left.\mathrm{F}(3,482)=89.10 ; p<.001\right)$. 
Table 8. Regression analysis of dimensions of perceived PLC for predicting CE at the overall level $(\mathrm{N}=486)$

\begin{tabular}{lccccccc}
\hline PLC dimension & $B$ & $\begin{array}{c}\text { Standard } \\
\text { error }\end{array}$ & $\beta$ & $t$ & $p$ & Zero-ordered $r$ & Part $r$ \\
\hline constant & 1.41 & .11 & & 12.42 & .000 & & .21 \\
core element & .19 & .04 & .23 & 4.73 & .000 & .51 & .53 \\
H and S resources & .20 & .04 & .25 & 4.78 & .000 & .53 & .21 \\
Structural condition & .17 & .05 & .21 & 3.72 & .000 & .53 & .17 \\
\hline
\end{tabular}

$R=0.60, R^{2}=0.36$

$F(3,482)=89.10, p=0.000$

Overall level $=1.41+0.19$ core element +0.20 human and social resources +0.17 structural condition

Table 9 showed the results of regression analysis of the prediction of perceived CE from PLC at the task analysis level. The table showed that teacher perceptions of CE at the task analysis level were significantly associated with each PLC dimension. The human and social resource dimension $(\beta=.25 ; p<.001)$ was apparently the best predictor of perceived CE. Core element $(\beta=.17 ; p=.001)$ and structural condition $(\beta=.16 ; p<.01)$ were also significantly associated with $\mathrm{CE}$ at the task analysis level. The PLC dimensions explained $26 \%$ of variance in perceived $\mathrm{CE}$ at the task analysis level $\left(\mathrm{R}=.51 ; \mathrm{R}^{2}=.26\right.$ and $\left.\mathrm{F}(3,482)=55.46 ; p<.001\right)$.

Table 9 . Regression analysis of dimensions of perceived PLC for predicting CE at the task analysis level

\begin{tabular}{lccccccc}
\hline $\begin{array}{l}P L C \\
\text { dimension }\end{array}$ & $B$ & $\begin{array}{c}\text { Standard } \\
\text { error }\end{array}$ & $\beta$ & $t$ & $p$ & Zero-ordered & Part $r$ \\
\hline constant & 1.51 & .14 & & 10.90 & .000 & & $r$ \\
core element & .16 & .05 & .17 & 3.28 & .001 & .42 & .15 \\
human and social resources & .23 & .05 & .25 & 4.39 & .000 & .46 & .20 \\
structural condition & .15 & .05 & .16 & 2.71 & .007 & .45 & .12 \\
\hline
\end{tabular}

$R=0.51, R^{2}=0.26$

$F(3,482)=55.46, p=0.000$

Task analysis level $=1.51+0.16$ core element +0.23 human and social resources +0.15 structural condition

Table 10 showed the results of regression analysis of the prediction of perceived CE from PLC at the group competence level. The table showed that teacher perceptions of CE at the group competence level were significantly associated with each PLC dimension. The core element dimension $(\beta=.23 ; p<.001)$ was apparently the best predictor of perceived CE. Human and social resources $(\beta=.21 ; p<.001)$ and structural condition $(\beta=.20 ; p=.001)$ were also significantly associated with $\mathrm{CE}$ at the group competence level. The PLC dimensions explained $31 \%$ of variance in perceived $\mathrm{CE}$ at the task analysis $\operatorname{level}\left(\mathrm{R}=.56 ; \mathrm{R}^{2}=.31\right.$ and $\mathrm{F}(3,482)=72.75 ; p<.001)$. 
Table 10. Regression analysis of dimensions of perceived PLC for predicting CE at the group competence level

\begin{tabular}{|c|c|c|c|c|c|c|c|}
\hline $\begin{array}{l}P L C \\
\text { dimensions }\end{array}$ & $B$ & $\begin{array}{c}\text { Standard } \\
\text { error }\end{array}$ & $\beta$ & $t$ & $p$ & $\begin{array}{c}\text { Zero-ordered } \\
r\end{array}$ & Part $r$ \\
\hline constant & 1.35 & .13 & & 10.51 & .000 & & \\
\hline core element & .21 & .05 & .23 & 4.56 & .000 & .48 & .20 \\
\hline human and social resources & .19 & .05 & .21 & 3.91 & .000 & .48 & .18 \\
\hline structural condition & .18 & .05 & .20 & 3.50 & .001 & .49 & .16 \\
\hline \multicolumn{8}{|l|}{$R=0.56, R^{2}=0.31$} \\
\hline$F(3,482)=72.75, p=0.000$ & & & & & & & \\
\hline
\end{tabular}

Group competence level $=1.35+0.21$ core element +0.19 human and social resources +0.18 structural condition

\section{Discussion}

This study examined the relationships among gender, school level, perceived PLC and perceived CE. The data analysis yielded the following interesting results. First, elementary school teachers significantly differed from secondary school teachers in perceived CE. The empirical data for Taiwan schools showed that a contextual factor, school level, affected the CE beliefs of teachers. This finding was, to some extent, in line with several other studies of west populations showing that school contextual factors affect teacher perceived CE (Adams and Forsyth, 2006; Bandura, 1993; Chester \& Beaudin, 1996; Hoy, Smith \& Sweetland, 2003; Knoblauch \& Woolfolk Hoy, 2008; Tschannen-Moran \& Woolfolk Hoy, 1998).

The literature shows that $\mathrm{CE}$ beliefs of teachers not only affect their self-referent efficacy perceptions, but also their beliefs about the conjoint capability of a school faculty. Within an organization, perceived CE represents the beliefs of group members concerning the performance capability of overall social system (Bandura, 1997; Hodges \& Carron, 1992; Peterson, Mitchell, Thompson, \& Burr, 2000). One of the earliest CE studies, which was performed by Bandura (1993), showed that CE is significantly and positively related to school-level achievement. Recent studies similarly show that CE not only presents that shared beliefs of teachers within their schools but also has a significant positive effect on student learning achievements (Goddard, Hoy, \& Woolfolk Hoy, 2000; Tschannen-Moran \& Barr, 2004). Some studies also indicate that CE explains the differences in teacher efficacy between schools (Goddard \& Goddard, 2001; Kurz \& Knight, 2004). Hence, the significant difference observed between elementary school and secondary school in the present study was expected. However, no evidence of gender differences in teacher-perceived CE was found.

School levels also significantly differed in one dimension of perceived PLC, core element, which was used to evaluate the teachers in terms of reflective dialogue, shared values and vision, shared practice, collective learning and application of learning. The data showed that elementary school teachers had the highest perceptions of peer interactions, including 
reflective dialogue, sharing values and practice, and collective learning and application. Generally, secondary school teachers in Taiwan a heavier teaching load and more pressure to prepare their students to pass entrance examination compared to elementary school teachers. This might explain the lower perceptions of secondary school teachers in core element of PLC. Indeed, in Taiwan, a great of secondary school teachers tend to believe they cannot attend PLC. Therefore, the number of PLCs is substantially lower in secondary schools than in elementary school.

Professional learning communities are grounded in two assumptions. First, knowledge is assumed to be gained by the day-to-day lived experiences of teachers and best understood through critical reflection with others who share the same experience. A second assumption is that actively engaging teachers in PLCs increases their professional knowledge and enhances student learning (Buysse, Sparkman, \& Wesley, 2003; DuFour, DuFour, \& Eaker, 2006; DuFour, DuFour, \& Eaker, 2008; Vescio, Ross, Adams, 2008). A review of eleven empirical studies of the impact of PLC suggested that well-developed PLCs positively improve the teaching practices of teachers and the learning activities of students (Vescio, Ross, Adams, 2008). Conversely, the present study revealed that secondary school teachers often choose not attend PLC because of the pressure to help improve the academic achievements of their students. This shows that efforts are needed to increase the awareness of PLC in secondary school teachers in Taiwan and to create an environment that encourages them to commit to working collaboratively in ongoing process of collective inquiry, reflective dialogue, sharing practice in order to achieve better results for the students they serve.

Another interesting finding was a positive correlation between PLC and perceived CE. This suggested that PLC has a role in teacher-reported levels of CE. This result also provides initial evidence that the variation between schools in PLC may be explained by the CE of a school. Teacher-perceived PLC was high in schools that had high CE. Conversely, low PLC was associated with low teacher-perceived CE. Although no universal characteristics of PLCs have been established, the consensus view of educational researchers is that a PLC exists in a school when a group of teachers collaboratively and critically exchange their instructional practices in a learning-oriented and growth-promoting way to support innovation and knowledge sharing (Mitchell \& Sackney, 2000; Stoll \& Louis, 2007; Toole \& Louis, 2002). A CE can be defined as the shared beliefs of a group in its conjoined capabilities to execute the courses of action required to achieve assigned goals (Bandura, 1997). Hence, perceived PLC significantly correlates with perceived CE. This suggests that schools should encourage to build open and collaborative PLCs for promoting teacher CE.

Third, perceived PLC was a significant predictor of perceived CE, which corroborates the claim in Senge et al. (2000) and in Adams and Forsyth (2006) that core properties of organizations are human capital and social networks, not organizational structures. That is, relationships among colleagues are more valuable to an organization than the specific structure that governs such interactions. One valuable outcome of positive social interaction is the potential generation of CE sources. Human capital and social networks, peer interaction, sharing belief, practice, all of which are core characteristics of a PLC, have been identified as factors in teacher CE (Newmann, Rutter, \& Smith, 1989; Zaccaro, Blair, Peterson, \& Zazanis, 
1995). This suggests that schools should be encouraged establish PLCs to develop the collective responsibility of teachers for improving student learning performance and school-level achievement.

Moreover, with respect to group competence assessment, one PLC dimension, core element, was the strongest predictor of perceived CE. This suggests that professional dialogues such as reflective teaching, sharing beliefs, and teaching practices, are important school contextual features that are systematically related to teacher beliefs about the competence of the faculty. Hence, creating professional dialogues in schools may offer a new possibility for enhancing teacher overall teaching effectiveness. On the other hand, regarding assessment of teaching tasks, another PLC dimension, human and social resource, was the best predictor of perceived CE. This suggests that school resources, including school's physical conditions and human capacities have a very important effect on what teachers believe is required for effective teaching. This indicates the need for schools to have appropriate physical equipment and to make efforts to create a collegial atmosphere so that teachers can collaboratively and critically exchange their instructional practices and support innovation and knowledge sharing.

\section{Conclusion}

The literature suggests that teacher perceptions of PLCs, individual characteristics, and school factors may affect perceived CE. To examine these hypotheses, the study analyzed the relationships among teacher perceptions of PLC, CE, gender, and school level in 486 teachers from elementary and secondary schools in Taiwan. When judging collective efficacy, two key elements were task analysis and assessment of group competence. The finding showed a positive correlation between teacher-perceived PLC and CE, and perceived PLC could indeed predict perceived CE. At task analysis level, the PLC dimension human and social resource was the best predictor of perceived CE. At group competence level, the core element was the best predictor. This study also revealed that elementary school teachers differed significantly from their secondary school counterparts in perceived CE.

This study is generally consistent with the literature regarding the core characteristics of a PLC, such as teacher reflective dialogue, shared values and vision, shared practice, collective learning and application of learning, physical conditions and human capacities of the school, all of which affect teacher CE (Newmann, Rutter, \& Smith, 1989; Tschannen-Moran \& Woolfolk Hoy, 1998; Zaccaro, Blair, Peterson, \& Zazanis, 1995). School contextual factors, however, affected teacher-perceived collective efficacy belief (Adams \& Forsyth, 2006; Bandura, 1993; Chester \& Beaudin, 1996; Knoblauch \& Woolfolk Hoy, 2008; Hoy, Smith \& Sweetland, 2003). The present study not only provided empirical data for Taiwan schools, it also showed that PLCs have an role in enhancing teacher CE. Teacher CE significantly and positively affect student learning achievements (Bandura, 1997; Goddard, Hoy, \& Woolfolk Hoy, 2000; Tschannen-Moran \& Barr, 2004). Therefore, school principals should establish a trusting atmosphere among teachers and restructure schools as PLCs to provide support collective learning by teachers. This eventually contributes to improving the collective efficacy of teacher in teaching task and teaching competency of the faculty. 


\section{Acknowledgments}

The author would like to thank the National Science Council of the Republic of China, Taiwan for financially supporting this research under Contract No. NSC 101-2410-H-018-025-MY2.

\section{References}

Adams, C. M., \& Forsyth, P. B. (2006). Proximate sources of collective teacher efficacy. Journal of Educational Administration, 44(6), 625-642. http://dx.doi.org/10.1108/09578230610704828

Bandura, A. (1986). Social foundations of thought and action: A social cognitive theory. Englewood Cliffs, NJ. http://dx.doi.org/10.4135/9781446221129.n6

Bandura, A. (1993). Perceived self-efficacy in cognitive development and functioning. Educational Psychologist, 28(2), 117-48. doi:10.1207/s15326985ep2802_3

Bandura, A. (1997). Self-efficacy: The exercise of control, freeman. New York, NY.

Buysse, V., Sparkman, K. L., \& Wesley, P. W. (2003). Communities of practice: Connecting what we know with what we do. Exceptional Children, 69(3), 263-277.

Chester, M. D., \& Beaudin, B. Q. (1996). Efficacy beliefs of newly hired teachers in urban schools. American Educational Research Journal, 33(1), 233-257.

DuFour, R., DuFour, R., \& Eaker, R. (2006). Learning by doing: A handbook for professional learning community at work. Bloomington, IN: Solution Tree.

DuFour, R., DuFour, R., \& Eaker, R. (2008). Revisiting professional learning communities at work: New insights for improving schools. Bloomington, IN: Solution Tree.

Goddard, R.D. (2001). Collective efficacy: A neglected construct in the study of schools and student achievement. Journal of Educational Psychology, 93(3), 467-476.

Goddard, R. D., \& Goddard, Y. L. (2001). A multilevel analysis of the relationship between teacher and collective efficacy in urban schools. Teacher and Teacher Education, 17, 807-818.

Goddard, R. D., Hoy, W. K., \& Woolfolk Hoy, A. (2000). Collective teacher efficacy: its meaning, measure, and effect on student achievement. American Educational Research Journal, 37(2), 479-507.

Goddard, R.D., Hoy, W.K., \& Woolfolk Hoy, A. (2004). Collective efficacy beliefs: theoretical developments, empirical evidence, and future directions. Educational Researcher, 33(3), 3-13.

Hodges, L., \& Carron, A.V. (1992). Collective efficacy and group performance. International Journal of Sport Psychology, 23, 48-59.

Hord, S. M. (1997). Professional learning communities: Communities of continuous inquiry 
and improvement. Austin: Southwest Educational Development Laboratory.

Hord, S. M. (2004). Learning together, learning together: Changing schools through professional learning communities. New York: Teachers College Press.

Hoy, W. K., Smith, P. A. and Sweetland, S. R. (2003). A test of a model of school achievement in rural schools: the significance of collective efficacy. In W. K. Hoy, \& C. G. Miskel (Eds.), Theory and research in educational administration, 1 (pp. 185-202). Greenwich, CT: Information Age Publishing.

Knoblauch, D., \& Woolfolk Hoy, A. (2008). Maybe I can teach those kids. The influence of contextual factors on student teachers' efficacy beliefs. Teaching and Teacher Education, 24(1), 166-179. Http://dx.doi.org/10.1016/j.tate.2007.05.005

Kruse, S. D., \& Louis, K. S. (1993). An emerging framework for analyzing school-based professional community. Paper presented at the annual meeting of the American Education Research Association, Atlanta, GA, April, 12-16, 1993. ED document 357537.

Kurz, T. \& Knight, S. (2004). An exploration of the relationship among teacher efficacy, collective teacher efficacy, and goal consensus. Learning Environments Research, 7(2), 111-128. http://dx.doi.org/10.1023/B:LERI.0000037198.37750.0e

Lee, J. C., Zhang, Z., Yin, H. (2011). A multilevel analysis of the impact of a professional learning community, faculty trust in colleagues and collective efficacy on teacher commitment to students. Teaching and Teacher Education, 27, 820-830. http://dx.doi.org/10.1016/j.tate.2011.01.006

Mitchell, C., \& Sackney, L. (2000). Profound improvement: Building capacity for a learning community. Lisse, NL: Swets \& Zeitlinger.

Newmann, F. M., Rutter, R. A., \& Smith, M. S. (1989). Organizational factors that affect school sense of efficacy, community, and expectations. Sociology of Education, 62, 221-238.

Peterson, E., Mitchell, T., Thompson, L. and Burr, R. (2000). Collective efficacy and aspects of shared mental models as predictors of performance over time in work groups. Group Processes and Intergroup Relations, 3(3), 296-316. http://dx.doi.org/10.1177/1368430200033005

Senge, P.M., Cambron-McCabe, N., Lucas, T., Smith, B. and Dutton, J. (2000). Schools that learn: a fifth discipline field book for educators, parents, and everyone who cares about education. New York: Currency Doubleday. Http://dx.doi.org/10.1007/s10833-006-0001-8

Stoll, L., Bolam, R., McMahon, A., Wallace, M., \& Thomas, S. (2006). Professional learning communities: a review of the literature. Journal of Educational Change, 7, 221-258.

Stoll, L., \& Louis, K. S. (2007). Professional learning communities: elaborating new approaches. In L. Stoll, \& K. S. Louis (Eds.), Professional learning communities: Divergence, depth, and dilemmas (pp. 1-14). Berkshire, England: Open University Press.

Thompson, S. C., Gregg, L., \& Niska, J. M. (2004). Professional learning communities, 


\section{Macrothink}

leadership, and student learning. Research in Middle Level Education Online, 28, 1-15.

Toole, J., \& Louis, K.S. (2002). The role of professional learning communities in international education. In K. Leithwood \& P. Hallinger (Eds.), The second international handbook of educational leadership (pp. 245-279). Dordrecht, Neth.: Kluwer. http://dx.doi.org/10.1007/978-94-010-0375-9_10

Tschannen-Moran, M., \& Barr, M. (2004). Fostering student learning: the reslationship of collective teacher efficacy and student achievement. Leadership and Policy in Schools, 3, 189-209.

Tschannen-Moran, M., \& Woolfolk Hoy, A. (1998). Teacher efficacy: its meaning and measure. Review of Educational Research, 68(2), 202-248. http://dx.doi.org/10.3102/00346543068002202

Vescio, V., Ross, D., \& Adams, A. (2008). A review of research on the impact of professional learning communities on teaching practice and student learning. Teaching and Teacher Education, 24, 80-90. http://dx.doi.org/10.1016/j.tate.2007.01.004

Zaccaro, S. J., Blair, V., Peterson, C., \& Zazanis, M. (1995). Collective efficacy. In J. E. Maddux (Ed.), Self-efficacy, adaptation, and adjustment: Theory, research, and application (pp. 305-328). New York: Plenum Press. 